neurodevelopmental risk (pulmonary pathology, intracranial haemorrhage) were the cause of death in 15 (19.2\%); however, in additional $44(56.4 \%)$ cases causes of death were indirectly associated with neurodevelopmental risk, except 19 (24.4\%) deaths caused by congenital malformations.

In preterm infants without neurodevelopmental risk factors, the incidence of CS and vaginal delivery were similar. Premature infants with conditions related to neurodevelopmental risk were more frequently delivered by CS as a means to prevent neurological and other impairments and perinatal death.

\section{$4 \quad$ TAKING REGULAR BREAKS IS IMPORTANT TO MAINTAIN THE HEALTH AND WELLBEING OF ALL STAFF MEMBERS, WHILST ENSURE THAT A HIGH STANDARD OF PATIENT CARE IS DELIVERED CONTINUOUSLY}

Lizaveta Collins*, Anddrea Turner, Jalaludin Weisuddin, Sheeren Parker. East Sufolk and North Essex NHS Trust. Colchester Hospital

\subsection{6/archdischild-2021-europaediatrics.4}

Aim As the volume and complexity of paediatric problems, including medical and social issues continues to rise, there remains limited guidance for paediatrics doctors to strike the balance between achieving satisfactory patient care and prevent themselves from developing work fatigue. The aim of the questionnaire was to review current staff break policy and confirm that this was being adhered to within the workplace. Where this was not taking place, the questionnaire looked to identify whether there was risk to patient safety and whether the health and wellbeing of workers was being effected.

Methods We conducted a survey at the District General Hospital, which included 9 questions and where 33 Doctors were anonymously interviewed. Of these 33 Doctors, 12 were Consultant Paediatricians, whilst 21 were junior doctors FY1 FY2. The Paediatrics and GP trainees from ST1 to ST6.

Result $94 \%$ of interviewees confirmed that they had days were they would not have breaks at all. $70 \%$ admitted that they felt guilty taking breaks, whilst $79 \%$ confirmed that senior members of staff had prevented them from taking breaks. 79\% answered that planning breaks during handover/ takeover is not acceptable, whilst overall, 91\% believe that senior members of staff should be actively seen to monitor/ enforce taking of breaks. All interviewees confirmed that a break should constitute time free from holding the bleep, where they would be permitted to take fluids and food on board.

It was also pointed out that a break should constitute time outside of the unit, preferably in an environment where an individual could relax.

Conclusion Based on the findings and review of various literature, it is recommended that a 30 minute break be provided and after 6 hours of continuous work. This would comply with the Trust. Where members of staff are required to work at commuter more than $1.5 \mathrm{hrs}$ daily, a 10 minute break is to be taken. For each shift, a senior doctor is to be identified and who will monitor whether staff are taking breaks. To promote wider cultural awareness, a poster and flyer was put up on notice boards for all staff members to view. These visual aids encourage staff to take breaks whilst also serve as an educational piece, reminding all staff members of the importance of the having rest: to ensure a high standard of patient care is maintained, as well as maintain individual health \& wellbeing.

\section{THE FREQUENCY AND MAGNITUDE OF THE IMPACT OF SOURCES OF NEGATIVE VACCINATION INFORMATION ON PARENTS' VIEWS ON VACCINE SAFETY AND EFFICACY}

Željko Pavić, Giovana Armano, Vesna Bacalja, Irena Bralić, Rasema Bubica Marija Čatipović, Sonja Horović, Matea Jelavić, Milivoj Jovančević, Zdenka Konjarik, Vlado Krmek, Miroslav Kudlač, Anica Persoglia-Petrac, Jadranka Petrović-Schneider, Dragica Šakić, Nevena Švorinić, Aida Mujkić. Faculty of Humanities and Social Sciences

10.1136/archdischild-2021-europaediatrics.5

The aim of the study was to determine the frequency of skepticism in relation to vaccination in parents with young children, the impact of demographic variables on skepticism, as well as the frequency of negative sources of information and the strength of their association with skepticism towards vaccination. Efforts were made to determine whether the most common sources of negative vaccination information were at the same time sources of negative information leading to the strongest skepticism.

An online questionnaire distributed by 15 pediatricians from Croatia included a sample of parents with at least one child between the ages of 1 and $4(\mathrm{~N}=333$, with a response rate of 96\%). The questionnaire was developed by the European Academy of Paediatrics Research in the Outpatient Setting Network (EAPRASnet). In the linear regression analysis, the scale obtained by summing the results to 14 Likert-type items was used as the criterion variable. The sources of negative vaccination information and demographic variables were used as predictor variables.

The arithmetic mean of scores of non-confidence in the safety and efficacy of the vaccine was $27.76(\mathrm{SD}=6.87$; the maximum possible score was 60 indicating higher degree of skepticism, while the lowest possible score was 14). About $13.5 \%$ of parents delayed and $6.9 \%$ refused to vaccinate their child for reasons other than illness and allergy. Negative vaccination information was received by $81.4 \%$ of parents, the most important source being the mass media (43.4\%), followed by friends and family members $(32.0 \%)$, the Internet $(22.1 \%)$ and healthcare professionals (2. 6\%). Health professionals' impact on the suspicion of vaccines was the strongest (regression coefficient amounts to 9.27 relative to the mass media), followed by friends and family, the Internet, and the mass media. The total number of children was positively correlated (regression coefficient equals 0.15 ), while age, sex, age of the youngest child, and parental education were not associated with skepticism regarding the safety and efficacy of vaccination.

The results of the research show that it is necessary to distinguish between the frequency and the strength of influence of certain sources of negative vaccination information, that is, although very rarely present as sources of negative information, health workers appear as a particularly powerful influence factor. Friends and family are moderately frequent and moderately strong, the mass media very frequent and very weak, and the Internet moderately frequent and weak source of negative information. 